\title{
A produção de livros moralizantes em Santa Cruz de Coimbra e Alcobaça entre os séculos XIV e XV
}

\author{
The production of moralizing books in Santa Cruz de Coimbra and Alcobaça \\ between the fourteenth and fifteenth centuries
}

Leandro Alves Teodoro *

\begin{abstract}
Resumo
Os scriptoria dos mosteiros de Santa Cruz de Coimbra e de Alcobaça ajudaram, entre os séculos XIV e XV, a disseminar, por diferentes regiões de Portugal, vários ensinamentos de ordem moral, ou melhor, começaram a elaborar obras não só para consumo próprio, mas também para atender outras plagas desse reino. Tendo em vista o comprometimento moralizante de tais instituições monásticas, o objetivo do presente artigo é perscrutar o papel de parte de suas obras na fabricação e fixação de um vocabulário, em língua portuguesa, que passou a nomear práticas vistas como virtuosas e louváveis pelas principais autoridades da Igreja desse período, bem como é examinar a relevância atribuída aos livros redigidos em vernáculo na formação moral de clérigos considerados insipientes. Mais precisamente, este trabalho busca questionar em que medida um grupo de livros, nomeadamente tratados prescritivos e hagiografias, se tornou suporte para termos e expressões que os clérigos regulares e seculares precisavam memorizar para aprenderem a instruir os fiéis cristãos.
\end{abstract}

Palavras-chaves: idade média; Portugal; mosteiros; livros; produção normativa.

\begin{abstract}
The scriptoria at the monasteries of Santa Cruz of Coimbra and of Alcobaça helped spread out, between XIV and XV centuries, through different regions in Portugal, several teachings of moral order, i. e. words started to be elaborated not only for one's own consumption, but also to attend to other places of such a Kingdom. Having in mind the moralizing compromising of such monastic institutions, the present article tries to scrutinize the role of parte of its works in building and fixing a vocabulary in Portuguese, which designates practices seen as virtuous and praiseworthy by the main authorities from the Church of that period. With emphasis therefore on prescriptions coming from the monasteries, the goal of this study is thus to investigate the role that the works produced in the vernacular religious scholars should play in the moral formation of the clergy considered ignorant. More precisely, the propose of this study is to examine the function of a group of books, namely presctiptible treaties and hagiographies as a support for terms and expressions which regular and secular clergymen should memorize and transmit to the Christian faithful.
\end{abstract}

Keywords: middle age; monasteries; books; production rules.

\footnotetext{
Artigo recebido em 12 de novembro de 2013 e aprovado em 02 de Dezembro de 2014.

* Doutor em História e Cultura Social. Faculdade de História, Direito e Serviço Social - UNESP. País de origem: Brasil. Faz pós-doutorado, com bolsa FAPESP (Fundação de Amparo à Pesquisa do Estado de São Paulo), sob a supervisão da professora Drạ. Susani Silveira Lemos França. E-mail: teodoro400@yahoo.com.br.
}

Horizonte, Belo Horizonte, v. 12, n. 36, p. 1369-1383, out./dez. 2014 - ISSN 2175-5841 


\section{Considerações iniciais}

No ano de 1477, o arcebispo de Braga, D. Luís Pires, resolveu denunciar as falhas na formação básica de seus subordinados ao proferir, durante um sínodo diocesano, a seguinte impressão: "nas igrejas e nos mosteiros deste arcebispado, achamos muitos clérigos e religiosos que não sabem ler e nem querem saber." (SYNODICON HISPANUM, 1982, v. 2, p. 100). Em outra altura da prédica, atacando mais diretamente os monges e cônegos, assevera que a ignorância dos religiosos nasce, sobretudo, "porque não procuram ler o texto de sua Regra." Na ânsia de constranger os membros do clero desobedientes e de incentivá-los a conhecer os ditames morais de seu grupo, julgou necessário não apenas apregoar, diante da clerezia local, críticas como essas, mas também propor medidas que considerava punitivas, como a criação de uma multa no valor de "três cruzados de ouro" a ser paga pelos religiosos bracarenses que não liam a Regra de sua ordem. (SYNODICON HISPANUM, 1982, v. 2, p. 143).

Em sintonia com D. Luís Pires, outro prelado desse mesmo arcebispado de Braga, D. Diogo de Sousa, afirmou, no ano de 1505, "que, entre as coisas necessárias ao sacerdote, está a ciência. Por isso, este deve saber a gramática para que entenda as coisas que, de fato, deve aprender como os cânones penitenciais e outras coisas de sua ordem e de seu ofício" (SYNODICON HISPANUM. 1982, v. 2, p. 164). Para esse arcebispo, os clérigos bracarenses não iniciados na gramática, isto é, na arte de ler e de escrever, deveriam ser proibidos de exercer qualquer atividade litúrgica ou administrativa nas paróquias, pois não teriam os requisitos necessários para ministrar os sacramentos da Igreja (SYNODICON HISPANUM, 1982, v. 2, p. 143). Tais regras promovidas por D. Luís Pires e D. Diogo de Sousa dão, portanto, sugestivas pistas sobre a maneira como os eclesiásticos eram estimulados por seus superiores para reverem suas práticas e começarem seus 
estudos sobre a palavra divina. (GARCIA Y GARCIA, [198?]). ${ }^{1}$

Na passagem do século XIV ao XV, com a finalidade de inserir no universo vocabular dos clérigos julgados ignorantes o nome de ações consideradas virtuosas e louváveis, os priores de S. Cruz de Coimbra e de Alcobaça - entre outras autoridades eclesiásticas - diminuíram a produção de obras redigidas em latim para elaborar diferentes tipos de livros em língua portuguesa, isto é, na mesma língua de seus interlocutores. Foi, por exemplo, o que propôs o frade Álvaro da Mota, ao apregoar, em meados do século XV, que "trasladou do latim para linguagem" a Vida de D. Telo, na expectativa de que um largo público pudesse ler essa obra (HAGIOGRAFIAS DE S. CRUZ DE COIMBRA, 1998, p. 273). Mais precisamente, nesse período, conforme os prelados passavam a questionar as ações de seus subordinados, aumentava, como será analisado, o número de eclesiásticos eruditos imbuídos de uma dupla tarefa: justificar a importância da produção de livros em vernáculo voltados para o aperfeiçoamento moral dos fiéis e inventariar termos e expressões que os clérigos precisavam apreender.

\section{0 papel moralizante dos livros}

No Livro dos Ofícios, recompilado pelo infante D. Pedro, no século XV, um dos integrantes célebres da corte de Avis, Cícero havia alertado que os livros deviam despertar "em alguns não somente o estudo de ler, mas ainda o de escrever" (CÍCERO, 1948, p. 95). Orientando-se por esse indicativo, tal corte preocupou-se em difundir a leitura, sem esquecer também da necessidade de se confeccionar boas obras. O pai de D. Pedro, D. João I, retoma uma tópica das obras medievais sobre a importância da escrita, ao explicar que, para os saberes não se perderem, os homens começaram a fazer "livros de gramática, retórica e outros livros que falam

\footnotetext{
${ }^{1} \mathrm{O}$ pesquisador francês Pierre Michaud-Quentin, ao analisar uma parcela das críticas direcionadas aos párocos, aventa, pois, a hipótese de que os eclesiásticos mais experientes tomaram para a si a tarefa de elaborar obras recheadas de lições morais para auxiliar os clérigos rudes a aperfeiçoarem suas práticas sociais (MICHAUD-QUENTIN, 1970, p. 76-91). Na mesma esteira, António Garcia y Garcia explorou a produção sinodal elaborada tanto em Castela como em Portugal para defender que um dos alvos prediletos dos bispos, entre os séculos XIV e XV, era a admoestação dos párocos despreparados para ofertar os sacramentos da Igreja aos fiéis (GARCIA Y GARCIA, [2000]).
} 
de muitas coisas" (D. JOÃO I, 1981, p. 7). Complementando seu ponto de vista, em outra passagem do Livro de Montaria, D. João I anuncia que "os livros foram feitos para aqueles que não sabem e querem aprender" e também foram feitos "porque o saber é grande e a memória não poderia retê-lo todo" (D. JOÃO I, 1981, p. 57). Nessas palavras, nota-se o empenho desse monarca para promover o aprendizado através dos livros, já que a memória individual, segundo ele, não conseguiria fixar tudo o que deveria ser aprendido para a pessoa seguir uma vida reta no futuro (GEARY, 1994, p. 142-155). Os príncipes dessa corte notaram, na verdade, que uma das formas de se conhecer a Deus a fundo e os frutos que ele tem a nos oferecer seria a partir do conhecimento livresco. Tanto é que o filho de D. João I, D. Duarte, no Leal Conselheiro, diz que ler bons livros faz com que o homem aproveite seu tempo, enriqueça sua sabedoria e, quando estiver ocioso, ocupe sua cabeça com bons pensamentos (D. DUARTE, 1998, p. 10).

Entre os séculos XIV e XV, o livro, por textualizar um complexo corpus doutrinário, destacou-se como um dos principais mecanismos dirigidos para o ordenamento social, ajudando a promover as normas de conduta que precisavam ser aceitas pelos príncipes, nobres e eclesiásticos. ${ }^{2}$ Mas nem todos os tipos de livros eram admissíveis no âmbito da corte no século XV. Ao buscar definir um tipo ideal de leitura, na Crónica de D. Pedro de Meneses, o cronista régio Gomes Eanes de Zurara, segundo cronista-mor e guarda-mor da Torre do Tombo 3, censura aqueles "muitos autores cobiçosos em ornamentar suas obras com histórias de festas, jogos em tempos alegres”, escritos “em que não se seguia outra coisa senão a deleitação” (ZURARA, 1997, p. 178-179). Com essas palavras, o cronista procura criticar certos livros confeccionados somente para distração da corte, pois a escrita deveria servir para um fim enobrecedor, isto é, devia ter ela uma finalidade moral. Por esse motivo, o incentivo à leitura começava com a seleção do que podia ou não ser lido no séquito régio.

\footnotetext{
${ }^{2}$ Entre os séculos XIV e XV, em diversas plagas, na medida em que o poder monárquico vai conseguindo estruturar suas bases e ter para si o controle fiscal e militar do espaço reinol, passou-se a adotar o livro não só como instrumento administrativo, mas também como suporte para as regras sociais (BLANCHARD; MÜHLETHALER, 2002, p. 188).

${ }^{3} \mathrm{O}$ cargo de cronista-mor foi fundado, em 1434, por D. Duarte, para que a escrita da história do reino fosse elaborada por um oficial de confiança do rei. (SERRÃO, 1989, p. 9-15).
} 
A produção e a manutenção dos livros não se restringiam, no entanto, apenas ao âmbito da corte de Avis. Muito antes de os reis dessa dinastia assumirem as rédeas administrativas do reino, os mosteiros de S. Cruz de Coimbra e de Alcobaça 4 já haviam erguido seus próprios scriptoria para confeccionar obras de teor moralizante. (SERRÃO, 1994, p. 285-301). Nesses espaços, os livros eram vistos como materiais dignos de fé, sendo usados para educar os fiéis e, sobretudo, os próprios eclesiásticos. Exemplo do quanto era significativo o livro no ambiente monástico era o fato de, na entrada das bibliotecas beneditinas, em Portugal, costumar estar fixada a seguinte frase: "O mosteiro sem biblioteca é como o rebanho sem redil, ou o claustro sem biblioteca é como o acampamento sem arsenal”. (LENCART, 1997, p. 129).

Graças aos monges copistas foi possível montar os primeiros acervos de livros do reino português entre os séculos XIII e XV. No Trezentos, mesmo se já existisse uma embrionária produção laical na corte dos reis de Borgonha ou no séquito do conde de Barcelos, os mosteiros se destacaram e suas obras foram vistas com veículo estratégico para a formação moral dos primeiros reis e prelados portugueses. (SARAIVA, 1998, p. 103-106). A título ilustrativo, o cronista Gomes Eanes de Zurara escreveu, em meados do Quatrocentos, que Fernão Lopes, o primeiro cronista-mor da Torre do Tombo, "despendeu muito tempo andando pelos mosteiros e igrejas" para ter informações acerca do reino, visitando locais onde pudessem ser encontrados documentos que fossem úteis para orientar a sua escrita (ZURARA, 1915, p. 13). Já o infante D. Pedro, em uma carta destinada ao mosteiro cisterciense de Alcobaça, pede emprestado um importante tratado de confissão, o Livro das confissões, de Martín Pérez. Nessa carta, ele diz: "faço-vos saber que a mim confortaria ter o traslado do livro de Martín Pérez que, nesse mosteiro, tem. Por isso, vos rogo e encomendo que me envie pelo Portador, e logo que eu tiver trasladado eu o mandarei de volta.” (PÉREZ, vol. 1, 2005, p. 21)). Essas

\footnotetext{
${ }^{4}$ Para um panorama geral acerca da história tanto de S. Cruz de Coimbra como de Alcobaça, pode-se ler Serrão, 1994, p. 285 -301.
} 
duas passagens ajudam a perceber, portanto, o valor que os nobres atribuíam aos acervos livrescos dessas instituições consideradas por eles fontes de obras raras.

As bibliotecas monásticas tornaram-se, pois, uma espécie de cofre, por salvarem do esquecimento um arsenal de lições moralizantes, ou melhor, as muralhas dos mosteiros protegiam não só a vida dos monges, mas tudo o que estava guardado ali dentro, como instrumentos litúrgicos e livros de diferentes gêneros. As paredes de S. Cruz de Coimbra serviram, por exemplo, para abrigar livros considerados, na época, de grande importância, como obras de S. Agostinho, a Imagem do mundo, de Gosuen de Metz, o Livro das Aves, a Etimologias, de S. Isidoro de Sevilha, entre outros. Já a biblioteca de Alcobaça ajudou a conservar um patrimônio de mais ou menos 500 códices manuscritos, acumulados entre os séculos XIII e XV (SARAIVA, 1998, p. 107-108), como algumas obras de S. Agostinho, S. Gregório Magno, Orígenes e de S. Ambrósio. Além de recompilar livros dos Padres da Igreja, o scriptorium deste mosteiro cisterciense também gozou de estabilidade e segurança para compilar tratados de confissão e outras obras prescritivas, destacando quatro livros: o Livro das confissões, de Martín Pérez, como antes anunciado, o Virgeu da consolação, de Jacob de Benavente, o Vita Christi, de Ludolfo da Saxónia, e o Orto do esposo, de um autor anônimo. Esse material foi fabricado pelos cistercienses de Alcobaça para ajudar clérigos regulares e seculares a resolverem vários quebra-cabeças a respeito dos mistérios divinos; por isso, um livro da biblioteca monástica não era para ser descartado após a leitura, e, sim, para ser guardado, relido e apreciado ao longo da vida.

No que diz respeito à elaboração do livro, o scriptor - monge copista escrevia por ditado, resultando o manuscrito em uma recriação auditiva de vários outros textos. A cópia, contudo, também podia ser feita no silêncio e, nesse caso, o monge copista repartia o manuscrito original em diversas partes, cada uma delas ficando sob a responsabilidade de um religioso para reproduzi-la. Tais manuscritos eram lidos no silêncio do claustro ou em voz alta no refeitório ou no próprio scriptorium. Os monges adotaram técnicas de escrita que pressupunham a existência de um leitor que lia em voz baixa, apenas com os olhos. Além disso, 
quando se lia em silêncio, a leitura era vista como mais penetrante e o leitor podia, assim, tirar um número maior de informações do texto (SAENGER, 1998, p. 215).

O cônego agostiniano Hugo de S. Victor, um dos principais responsáveis pela reforma do ensino da palavra divina no século XII, além de incentivar a produção de livros, buscou também construir um modelo ideal de leitor. Esse pensador cristão assevera, na obra Didascálicon, que "aquele que procura no sacro elóquio o conhecimento das virtudes e a regra de viver, deve ler, sobretudo, os livros que aconselham o desprezo deste mundo”. O bom leitor também precisa, segundo ele, saber que a leitura "deve ser uma exortação, não uma ocupação, e deve nutrir os bons desejos, e não matá-los.” (HUGO DE S. VICTOR, 2007, p. 221). Esse cônego explica, entretanto, que a leitura realizada sem aplicação e concentração perderia a sua eficácia e o leitor deixaria de contemplar satisfatoriamente as lições ofertadas pela obra. Tal letrado e muitos de seus congêneres mostravam-se convencidos de que seus aprendizes tinham de se tornar, antes de tudo, bons leitores e conhecedores assíduos da Sagrada Escritura. Nesses tempos, ganhou fôlego, portanto, a ideia de que a leitura dava as coordenadas certas para o religioso saber se enquadrar nas bases morais de sua ordem (CHARTIER; MARTIN, 1989, p. 81-83).

Os prelados portugueses dos séculos XIV e XV apregoaram, de maneira semelhante a Hugo de S. Victor, que seus subordinados não poderiam ler um livro por mera curiosidade. Para justificar a regra de que era preciso evitar leituras e conhecimentos vãos, o bispo D. Diogo Ortiz, na obra $O$ cathecismo pequeno escrita no ano de 1500 e editada em 1504 -, admite que a "curiosidade é estudo e desejo desordenado de saber ora seja pelos sentidos corporais ora pelo entendimento. Desordena o desejo quando [...] não é para bom fim, ou não por bons meios, ou quando se gasta tempo com o que não é útil e necessário ao seu estado e ofício." (D. DIOGO ORTIZ, 2001, p. 233). Impressão parecida fora descrita por S. Tomás de Aquino, um dos principais expoentes do pensamento escolástico, nessas palavras: "é vicioso o interesse com que alguns se empenham por aprender algo a mais com 
intenção pecaminosa." (TOMÁS DE AQUINO, 2013, v. 7, quest. 165, art. 01, p. 449). Para este pensador, até mesmo a vontade em conhecer as verdades divinas deveria ser ponderada para a leitura não se tornar um simples passatempo. Por meio de prédicas como essas e de outras ainda mais recheadas de informações, tanto Diogo de Sousa como o Doutor Angélico buscavam ensinar aos seus leitores que certos livros voltados para a promoção da palavra divina tinham de ser vistos como uma espécie de guia moral, isto é, um norte pelo qual saberiam chegar ao Paraíso.

Entre os séculos XIV e XV, as principais produções elaboradas em língua portuguesa pelos mosteiros de Alcobaça e de S. Cruz de Coimbra possuíam, portanto, uma razão de ser: fortalecer a disseminação de termos e expressões que designavam práticas virtuosas. Qualquer tentativa, contudo, de inventariar aqui a totalidade desse vocabulário não se encaixaria nos limites deste estudo e se tornaria irrealizável. Resta, pois, mostrarmos brevemente o destaque que certas palavras ganharam para designar ações específicas do modo de vida projetado para clérigos regulares e seculares na época em questão.

\section{As primeiras pinceladas em vernáculo}

Em $A$ vida de D. Teotônio, obra confeccionada no scriptorium do mosteiro português de S. Cruz de Coimbra, no início do século XII, mas com uma versão em língua vernácula do XIV, seu último compilador fez o seguinte comentário acerca da vida de seu retratado:

Ordenado, pois, ele sacerdote, começou a crescer com maior aproveitamento da prudência [...] Alguns louvavam ele [D. Teotônio] por nunca usar a curiosidade; outros porque nunca se deu às deleitações; outros porque nunca procurou honras e tampouco coisas semelhantes [...] (HAGIOGRAFIAS DE SANTA CRUZ DE COIMBRA, 1998, p. 290)

Ao descrever as principais etapas da vida desse prior, o compilador - um religioso crúzio - considera-o uma pessoa louvável por ser um modelo de homem prudente a ser seguido no presente e nos tempos vindouros. Do mesmo modo, na 
Vida de D. Telo, esta personagem é descrita como um varão que foi "muito casto do seu princípio de viver até seu fim" [...] (HAGIOGRAFIAS DE SANTA CRUZ DE COIMBRA, 1998, p. 281).

Pessoas, como D. Teotônio ou D. Telo, eram consideradas parâmetro de conduta, já que a descrição de suas virtudes ajudava a exemplificar certas prescrições sugeridas pelas principais autoridades da Igreja, dando, assim, corpo e vida aos valores esboçados como ideais nessa época. A partir dessas projeções, isto é, de uma escrita voltada para inspirar os cristãos a se conduzirem de maneira mais virtuosa no cotidiano, os crúzios procuravam estimular seus congêneres a reassumirem novos pactos com seus grupos; um acordo em que se comprometeriam, assim como D. Teotônio ou D. Telo, a recusar os prazeres proibidos do corpo. Para os crúzios, nada melhor, portanto, que a promoção da história de vida de homens que foram identificados por eles como exemplares para fazerem com que outros eclesiásticos aprendessem a evitar a companhia de mulheres lascivas, a não terem filhos e, sobretudo, a absorverem o significado de termos como "pureza”, "virgindade” e "controle da carne”.

A disseminação de hagiografias e de tratados monásticos contribuiu, entre outras metas, para a fixação no repertório da língua portuguesa de termos que designavam práticas virtuosas, isto é, abriu caminho para torná-los moedas correntes na rotina de muitos clérigos e leigos que não usavam o latim como sua principal língua. No que tange à construção em língua vernácula de regras acerca do controle dos impulsos indesejados do corpo, a versão alcobacense do livro Virgeu da Consolaçon assevera que "o pregador precisa ler e entender que não deve repreender quem despreza as coisas terrenas e deve se guardar para não cair nos prazeres da carne.” (VIRGEU DA CONSOLAÇON, 1959, p. 116). Em outra altura desse mesmo tratado, seu autor toma um ar mais enfático ao asseverar:

diz Basílio que assim como põem os freios nos cavalos, devemos enfrear as nossas carnes com jejuns. E não queiras dar esforço ao teu corpo para que queira lidar contra o espírito, mas sempre tenha a carne sujeitada ao espírito por tal que obedeça aos seus mandamentos (VIRGEU DA CONSOLAÇON, 1959, p. 68). 
Traduzindo trechos de grandes autoridades do pensamento cristão, como Basílio de Cesarea, Gregório Magno, Agostinho e Isidoro de Sevilha, a versão portuguesa desse tratado forneceu aos eclesiásticos longas pinceladas sobre as maneiras como deveriam seguir uma vida austera e prudente para se manterem preparados para exercer seus ofícios litúrgicos. Juízos como esses recheiam, do mesmo modo, a referida Vida de D. Teotônio, na qual o seu compilador, ao atentar para a forma como este cônego agostiniano protegia seu corpo, apregoa: Para não incorrer em alguma infâmia por causa de mulheres, nunca com elas quis falar sem estar presente uma testemunha [...] (HAGIOGRAFIAS DE SANTA CRUZ DE COIMBRA, 1998, p. 290). O próprio Teotônio reconhecia, segundo a hagiografia, que, quando alguma mulher queria com ele falar, não havia nenhuma que não podia deixar de suspeitar. Desconfiava, pois, de todas. Todavia, "amava-as irmãs". Foi com esse comportamento, segundo a hagiografia, que conquistou "a afeição dos homens e das mulheres." (HAGIOGRAFIAS DE SANTA CRUZ DE COIMBRA, 1998, p. 291).

Conselhos acerca dos cuidados a serem tomados com o corpo também ganharam destaque na versão em língua vernácula da Regra de S. Bento, obra produzida, em meados do século XV, pelos monges alcobacenses. Nesse opúsculo, é prescrita a seguinte admoestação aos religiosos de observância beneditina: "não importa quem tu sejas, precisas renunciar aos próprios deleites e prazeres da carne. Para tanto, toma armas muito fortes e nobres de obediência para servir a Jesus Cristo Senhor e verdadeiro Rei." (COLLECÇÕES DE INÉDITOS PORTUGUESES, 1829, p. 249). Ora, no universo monástico, os deleites da carne despertavam a atenção dos eclesiásticos mais eruditos, autores de tratados e manuais pedagógicos, que se interessavam em catalogar certas sensações corporais a serem evitadas não só por religiosos, mas também por clérigos seculares e até mesmo por leigos.

No que diz respeito ainda à construção de um inventário de práticas relativas ao controle dos prazeres do corpo, é importante dizer que o livro Orto do esposo é uma das obras monásticas que assume uma das posições mais extremadas, por estimular todos os fiéis, e não apenas clérigos regulares, a serem 
puros, virgens e cultivadores de valores cenobíticos. Explica o autor que a sua irmã lhe teria solicitado uma obra em língua vernácula que contivesse histórias sobre "as façanhas de nobres varões e das coisas maravilhosas do mundo”. Atendendo ao pedido, procurou redigi-la a partir de uma discussão sobre as principais lições morais da Bíblia e de escritos de grandes teólogos da época. A partir de um jogo de alegorias, em que cada vocábulo utilizado pode trazer um significado diferente do usual, a função didática da obra aparece mais claramente acentuada em passagens em que o compilador apresenta Cristo como uma espécie de esposo protetor da alma do bom cristão. Mas, como ressalta tal religioso, não era fácil enlaçar a alma com o filho de Deus. Para sentir a presença dele a seu lado, era necessário, pois, que o fiel absorvesse os valores de uma existência ascética. Esse tratado monástico desqualificava as práticas dos varões que esqueciam de que a carne é apenas um invólucro passageiro da alma. O Orto do esposo denuncia, por exemplo, os males provocados pelos deleites da carne em muitas de suas passagens, mas há uma que nos chama mais a atenção, pois nela é afirmado que “o corpo é uma carne bem pesada para o espírito suportar. Diz o Sabedor que o corpo, quando se corrompe, agrava o estado da alma” (ORTO, 1956, p. 306-307). A partir desse comentário, é sugerido que o homem acostumado com os deleites da carne jamais se saciaria, pois os vícios luxuriosos, ao contrário de serem supridos, se retroalimentariam infinitamente.

A ação dos monges que, dentre outros objetivos, tinha a meta de formar homens virtuosos, reforçava as predicações a favor da vida eclesiástica. Por isso, pode-se dizer que do mesmo modo que as hagiografias dos crúzios buscavam ensinar aos eclesiásticos por meio de exemplos de figuras que foram, em seu tempo, julgadas exemplares, os alcobacenses procuravam aperfeiçoar, por sua vez, as práticas dessa gente através de prescrições e conselhos que pudessem confortálos e, ao mesmo tempo, instruí-los.

Além de ensinar valores relativos ao controle dos prazeres da carne, outra tópica corrente no discurso alcobacense foram conselhos concernentes à formação 
do clérigo pregador. Sobre esse aspecto, a obra Virgeu da Consolaçon, assevera o seguinte:

diz S. Gregório que não pode ser prezada a pregação do homem de má vida. E diz esse mesmo que aqueles que pregam e dizem a palavra de Deus e a não colocam em obra podem ser chamados ladrões, porque tomam em si palavras de bons e de santos, as quais a eles não pertencem. Outrossim deve o pregador luzir por sabedoria, ensinando verdade, porque ele deve saber e ensinar as coisas que devemos fazer. E isto com palavras humildes. E guarde o pregador que não seja a pregação para agradar a si nem tome em si vã glória, mas a sua intenção seja para agradar a Deus e dar proveito aos homens. Aqueles que esperam louvor de sua pregação entre os homens são doestados pelo apóstolo S. Paulo, que os chamam homens que fazem adultério na palavra de Deus. Não façamos adultério na palavra de Deus. (VIRGEU DA CONSOLAÇON, p. 115)

Ao deslizar pelo perfil de pregador considerado ideal nesses tempos, uma das metas dessa obra é familiarizar não só os cistercienses, mas outros eclesiásticos portugueses com o nome das virtudes que deveriam almejar, como a "honestidade", a "humildade" e a "mansidão". Explica a obra que o eclesiástico para se tornar um cristão honesto e humilde, além de não poder apregoar, em público, nada que não estivesse contido diretamente nas páginas da Bíblia ou nos comentários desse livro, também deveria confessar seus erros para outro clérigo e não se eximir de reparar suas falhas, seja, em caso de furto, devolvendo o objeto roubado para a igreja ou, em caso de simonia, recuperando o material ilicitamente vendido.

Acerca da promoção desses mesmos valores, a versão alcobacense do Livro das confissões, de Martín Pérez, aconselha os clérigos a saberem que "quando não guardam seu estado em honestidade, nem rezam, nem cantam, nem cumprem seus ofícios, nem ministram os sacramentos como devem, são nestas coisas preguiçosos, negligentes e desleixados" (PÉREZ, 2005, vol. 1, p. 220). Esse mesmo tratado de confissão também ensina que o termo oposto ao vocábulo "honestidade" é a palavra "escândalo". Para essa obra, alguns dos principais escândalos que um clérigo poderia cometer eram a "lisonja, tomar conselhos com judeus sobre saúde de seus corpos, falar muito acerca das coisas do mundo e pouco das de Deus e jejuar e orar sem devoção" (PÉREZ, 2005, vol. 1, p. 218). Já no que diz respeito especificamente aos prelados, deixam de ser honestos, segundo a opinião desse mesmo Pérez, 
quando "trazem cães e aves para a igreja e andam a caçar pelas casas dos Reis e quando se encantam pelas honras do mundo e não pelas almas” (PÉREZ, 2005, vol. 1, p. 217). O Livro das confissões foi, na verdade, um dos maiores monumentos construídos em língua portuguesa, entre os séculos XIV e XV, não só porque definiu o nome das principais qualidades reconhecidas como inerentes ao clérigo exemplar, mas principalmente porque transladou para o vernáculo um conjunto vasto de outras expressões que designavam cada função dos sacramentos da Igreja.

\section{Considerações finais}

Pode-se dizer que a escrita em vernáculo, entre os séculos XIV e XV, ganhou fôlego, nos scriptoria de S. Cruz de Coimbra e de Alcobaça, a partir do momento em que abades, priores e prelados começaram a investir na formação moral dos clérigos insipientes, daqueles que não conheciam outra língua que não fosse o português. Nessa época, muitas autoridades eclesiásticas buscaram incentivar a produção de obras consideradas por eles fáceis de serem lidas e manuseadas, transladando, portanto, lições moralizantes redigidas em outras línguas, sobretudo em latim e castelhano, para o universo vocabular desses cristãos. Esses mesmos clérigos defendiam que a confecção de tratados e opúsculos, na mesma língua de seus subordinados, poderia ajudá-los a fazer uso de um novo vocabulário, em que termos como "castidade", "honestidade", "virgindade" e "escândalo" precisavam ser naturalizados, para que aprendessem a praticar ações vistas como virtuosas e louváveis no período em questão.

Os priores dos mosteiros de Alcobaça e de S. Cruz de Coimbra passaram, desse modo, a elaborar obras em português para promover desde a trajetória religiosa de homens julgados virtuosos, como a vida de D. Telo ou de D. Teotônio, até prescrições voltadas para o aperfeiçoamento das práticas comezinhas de seus subordinados. Em outras palavras, a política de combate à ignorância dos clérigos portugueses passou a apelar, nessa época, para a confecção de diferentes gêneros 
de livros que pudessem tornar inteligíveis para essa gente certas bases da moral cristã.

\section{REFERÊNCIAS}

BLANCHARD, J; MÜHLETHALER, J. Écriture et pouvoir. A l'aube des temps modernes. Paris : Dépôt Légal, 2002.

CHARTIER, R; MARTIN, J. Histoire de l'édition française. Paris : Fayard, 1989.

CÍCERO, M. T. Livro dos ofícios. O qual tornou em língua o infante D. Pedro. Ed. De Joseph M. Piel. Lisboa: Por Ordem da Universidade, 1948.

Coimbra: Real imprensa da Universidade, 1829.

COLLEÇÕES de inéditos portugueses. Organizado por Fortunato de S. Boaventura.

D. DIOGO ORTIZ. O Cathecismo pequeno. Ed. De Elsa Maria Branco da Silva. Lisboa: Edições Colibri, 2001.

D. DUARTE. Leal conselheiro. Edição crítica, introdução e notas de Maria Helena Lopes de Castro. Lisboa: Imprensa Nacional; Casa da Moeda, 1998.

D. JOÃO I. Livro da montaria. In: ALMEIDA, M. Lopes de. (Ed.).Obras dos príncipes de AvisPorto: Lello \& Irmãos Editores, 1981.

FORTUNATO de SÃo BoAventura (org.). Collecção de Inéditos Portuguezes dos séculos XIV e XV. Ttome I, Coimbra, 1829.

GARCIA Y GARCIA, António. Religiosidad Popular en los Sínodos Medievales Portugueses : In: Estudos em homenagem ao Professor Doutor Pedro Soares Martínez. Coimbra: Almedina, [2000].

GEARY, P. Phantoms of remembrance: Memory and oblivion at the end of the first millennium. Princeton: Princeton university press, 1994.

HAGIOGRAFIAS DE SANTA CRUZ DE COIMBRA. Vida de D. Telo, Vida de D. Teotónio e Vida de Martinho de Soure. Edição crítica de Aires A. Nascimento. Lisboa, 1998.

HUGO DE S. VICTOR. Didascálicon. Da arte de ler. Bragança paulista: Editora Universitária S. Francisco, 2007.

LENCART, L. O costumeiro do Pombeiro. Lisboa: Editorial Estampa, 1997.

MICHAUD-QUENTIN, P. Les méthodes de la pastorale, Xe-XVe siècles, Miscelleana medievala, n. 7, 1970, p. 76-91. 
ORTO DO ESPOSO. Ed. Bertil Maler. Rio de Janeiro: Ministério da Educação e cultura Instituto Nacional do Livro, vol. 1, 1956.

PÉREZ, Martín. Livro das confissões. Ed. de José Barbosa Machado e Fernando Alberto Torres. S. l: Publicações Pena Perfeita, vol. I, 2005.

SAENGER, P. La lectura en los últimos siglos de la Edad Media In: CHARTIER, R; CAVALLO, G. Historia de la lectura en el mundo occidental. Madrid: SantillanaTaurus, 1998.

SARAIVA, A, J. O Crepúsculo da Idade Média em Portugal. Lisboa: Gradiva, 1998.

SERRÃO, J. Cronistas do século XV posteriores a Fernão Lopes. Lisboa: Biblioteca Breve, 1989.

SERRÃO, J. Figuras e caminhos do Renascimento em Portugal. Lisboa: Imprensa Nacional-Casa da Moeda, 1994.

SYNODICON HISPANUM. Ed. António Garcia y Garcia e Isaias Rosa Pereira. Madrid: Editorial Católica, 1982, v. 2.

TOMÁS DE AQUINO. Suma teológica. São Paulo: Edições Loyola, 2013, v. 7.

VIRGEU DA CONSOLAÇON. Ed. Albino de Bem Veiga. Porto Alegre: Oficina do Globo, 1959.

ZURARA, G. E. Crónica da Tomada de Ceuta. Ed. Francisco Maria Esteves Pereira. Coimbra: Academia das Sciencias de Lisboa, 1915.

ZURARA, G. E. Crónica de D. Pedro de Meneses. Ed. de Maria Teresa Brocado. Lisboa: Fundanção Calouste Gulbenkian, 1997. 